\title{
Somatostatin inhibits gastric acid secretion after gastric mucosal prostaglandin synthesis inhibition by indomethacin in man
}

\author{
M H MOGARD, V MAXWELL, T KOVACS, G VAN DEVENTER, \\ J D ELASHOFF, T YAMADA, G L KAUFFMAN JR, AND J H WALSH
}

From the Center for Ulcer Research and Education, VA Wadsworth Medical/Surgical Services and UCLA, Los Angeles, California, USA.

SUMMARY The inhibitory effect of indomethacin, 200+200 mg administered per os over 24 hours, on the prostaglandin $\mathrm{E}_{2}$ generative capacity of gastric mucosal tissue was determined in healthy male volunteers. The effect of prostaglandin synthesis inhibition on somatostatin induced suppression of food-stimulated acid secretion was tested. Peptone meal stimulated acid secretion was quantified in five healthy volunteers by intragastric titration with and without indomethacin pretreatment. Somatostatin doses of 200,400 , and $800 \mathrm{pmol} / \mathrm{kg} / \mathrm{h}$ each significantly inhibited the peptone stimulated acid output. Indomethacin treatment, resulting in $90 \%$ inhibition of prostaglandin $\mathrm{E}_{2}$ synthesis, did not affect glucose- or peptone-stimulated acid output or modify the inhibitory action of somatostatin. Clinically, acid inhibition by somatostatin has been used to treat bleeding peptic ulcers. Ulcer haemorrhage may be preceded by an excessive use of drugs that inhibit prostaglandin synthesis such as aspirin or other non-steroidal anti-inflammatory agents. Recent observations in the rat indicate that prostaglandins mediate the inhibitory action of somatostatin on gastric acid secretion. The present results suggest that prostaglandins are not required for inhibition of gastric acid secretion by somatostatin in man.

The inhibitory action of somatostatin on gastric acid secretion has been well established in several species including man ${ }^{1}$ and the rat, ${ }^{2}$ but the mechanism of its action is not fully understood. Observations in the anaesthetised rat indicate that prostaglandins mediate the inhibitory action of somatostatin on gastric acid secretion. ${ }^{2}$ Thus, somatostatin promoted gastric release of prostaglandin $\mathrm{E}_{2}$, a potent local inhibitor of acid secretion, and indomethacin, a prostaglandin synthesis inhibitor totally blocked the inhibitory action of somatostatin. The present study examines the hypothesis that prostaglandins mediate the inhibitory action of somatostatin on gastric acid secretion also in man.

\section{Methods}

SUBJECTS

Five male volunteers (mean age 33 years, mean

Address for correspondence: Mats Mogard, MD, Center for Ulcer Research and Education, VA Wadsworth MC, Building 115, Los Angeles, CA 90073 , USA.

Received for publication 11 January 1985 weight $78 \mathrm{~kg}$ ) in good health and without history of gastrointestinal disorders were studied. The study was approved by the V A Wadsworth Human Studies Committee and informed consent was obtained from each subject. After an overnight fast, a double lumen tube was introduced into the stomach, through which test meals were administered. Liquid meal stimulated gastric acid secretion was quantified by intragastric titration to $\mathrm{pH} 5 \cdot 5 .^{3} \mathrm{~A}$ $5.5 \%$ glucose solution was administered during 30 minutes and followed by four consecutive $8 \%$ Bactopeptone (Difco Labs Inc.) meals $(45+3 \times 30$ $\min$ ).

All subjects were studied on three separate days. On one day somatostatin was dissolved in saline containing $0.25 \%$ human serum albumin and infused intravenously during the last three peptone meals at sequentially increasing doses each of $30 \mathrm{~min}$ duration; 200, 400, and $800 \mathrm{pmol} / \mathrm{kg} / \mathrm{h}$. A second day was identical but the subjects were pretreated with a $200 \mathrm{mg}$ dose of indomethacin (Indocin, MSD) per os on the day before and on the morning of the study. A third day was identical, but no somatosta- 
tin or indomethacin was administered. Gastric mucosal biopsies, four from antrum and four from corpus, were taken endoscopically before and after indomethacin treatment and the biopsies were pooled respectively from each of three of the subjects, for tissue prostaglandin $E_{2}$ generation assay. ${ }^{45}$

The results are presented as mean and standard error of the means. The ranges of acid output data are given in brackets. Repeated measured analysis of variance was used to evaluate significances of differences between the experimental groups; $\mathrm{p}<0.05$ was considered as significant.

\section{Results}

The gastric acid secretory responses to the glucose meal were $3 \cdot 0 \pm 0 \cdot 5(1 \cdot 6-4 \cdot 6), 2 \cdot 6 \pm 0.9(0 \cdot 7-6 \cdot 0)$ and $3.7 \pm 1.0(0.2-6.7) \mathrm{mmol} / 15 \mathrm{~min}$ in the control, the somatostatin-treated and the indomethacinsomatostatin group, respectively, (Figure). The peptone meal significantly stimulated acid output similarly in all groups to $6 \cdot 2 \pm 0 \cdot 8(3 \cdot 8-8 \cdot 8), 4 \cdot 9 \pm 0.7$ $(2 \cdot 2-6.9)$ and $6 \cdot 4 \pm 1 \cdot 5(1.6-11.0) \mathrm{mmol} / 15 \mathrm{~min}$ at 75 min, respectively. In the control group, acid output remained at this plateau level throughout the experiment. The 200,400 and $800 \mathrm{pmol} / \mathrm{kg} / \mathrm{h}$ doses of somatostatin each significantly reduced the acid output to $3.0 \pm 0.3(2.0-4.0), 0.7 \pm 0.2(0-0.1)$ and $0 \pm 0.0(0-0.1) \mathrm{mmol} / 15 \mathrm{~min}$ respectively, in the somatostatin group. Corresponding values for the indomethacin-somatostatin group were $2 \cdot 1 \pm 0.7$ $(0.6-4.4), 0.4+0.2(0-1.2)$ and $0.1 \pm 0.1(0-0.5)$

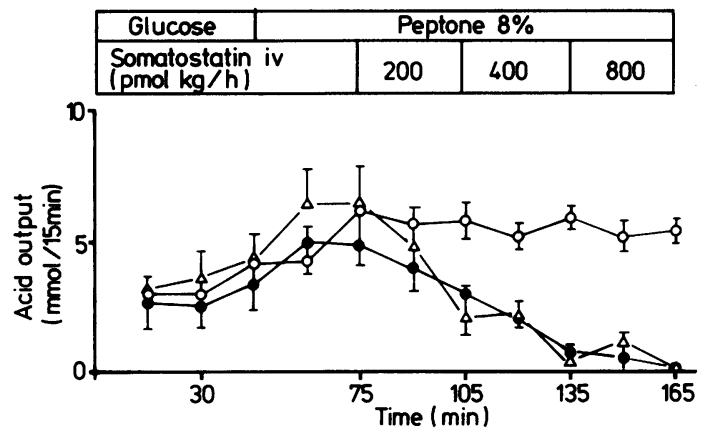

Figure Glucose-and peptone-stimulated gastric acid secretion quantified by intra-gastric titration in five healthy volunteers. Effect of iv somatostatin infusion (O), indomethacin pretreatment followed by iv somatostatin infusion $(\triangle)$, or control $(O)$. Somatostatin, at 200,400 , and $800 \mathrm{pmol} / \mathrm{kg} / \mathrm{h}$ iv, significantly inhibited acid output as compared with control; $p<0 \cdot 05$. Indomethacin treatment did not affect glucose-or peptone-stimulated acid output, or the inhibitory action of somatostatin. $\bar{x} \pm S E, n=5$. $\mathrm{mmol} / 15 \mathrm{~min}$. Plateau levels of inhibition were not reached with the individual somatostatin doses. There was no significant effect of indomethacin on glucose- or peptone-stimulated acid secretion, or on somatostatin induced reduction of acid output.

Indomethacin treatment significantly reduced the prostaglandin $E_{2}$ generative capacity of antral and corpus gastric mucosal tissue of $16.6 \pm 8$ and $9.7 \pm 2$ to $1.4 \pm 1$ and $1.0 \pm 1 \mathrm{ng} / \mathrm{min} / \mathrm{g}$, amounting to $91 \%$ and $90 \%$ inhibition respectively. The corresponding tissue weights, of pooled four biopsies from each of three subjects, were $40 \cdot 2 \pm 2$ and $44 \cdot 2 \pm 3 \mathrm{mg}$. No subject experienced any side effect.

\section{Discussion}

Prostaglandin synthesis inhibition by indomethacin failed to affect the inhibitory action of somatostatin in man in the present study. This observation is in contrast to findings in the anaesthetised $\mathrm{rat}^{2}$ and may show a species difference.

Somatostatin may act locally either indirectly by interacting with hypothetical receptors on G-cells and reducing the release of gastrin, ${ }^{6}$ or directly by interacting with receptors on the parietal cells. ${ }^{3}$ At the cellular level, the mechanism of somatostatin action is not well understood. Its action may be because of inhibition of cyclic AMP production as this substance was strongly reduced in rat gastric glands by somatostatin. ${ }^{8}$ Some prostaglandins inhibit parietal cell cyclic AMP production ${ }^{9}$ and are potent inhibitors of acid secretion. In accordance with these observations somatostatin enhanced prostaglandin release and its inhibitory action on acid secretion could be abolished by indomethacin in the anaesthetised rat. ${ }^{2}$ Hence, prostaglandins may mediate inhibition of gastric acid secretion by somatostatin in the rat, but not in man.

The potential role of endogenous prostaglandins in the regulation of acid secretion remains controversial. Indomethacin induced inhibition of prostaglandins, verified by prostaglandin generation assay, did not affect basal or stimulated acid output which is in agreement with some investigators ${ }^{10}$ but in contrast with others. ${ }^{11}$ The present findings do not support a major physiological role for prostaglandins in the regulation of glucose- or peptonemeal-stimulated acid secretion in man.

Clinically, somatostatin has been used to treat bleeding peptic ulcers and haemorrhagic gastritis. ${ }^{12}$ Although this peptide is known to reduce gastric blood flow, ${ }^{13}$ its haemostatic effect on gastric bleedings is likely to be secondary to its inhibitory action on acid secretion. Gastric haemorrhage may be preceeded by an excessive use of drugs that inhibit prostaglandin synthesis such as aspirin or 
other non-steroidal anti-inflammatory agents. ${ }^{14}$ The present results indicate that somatostatin may be used successfully to inhibit gastric acid secretion in patients who have received any of these commonly used drugs, because somatostatin can inhibit acid secretion by a prostaglandin independent mechanism in man.

This study was supported by and grants from the National Institute of Health, Am 17294, Am 17328 and Am 08354, and Veterans Administration. Mats Mogard was, in part, supported by Söderbergs Stiftelse and Karolinska Institutet, Stockholm, Sweden. Somatostatin was generously supplied by Serono Lab Inc, MA, USA. The technical assistance of Mayda Pehlevanian is greatfully acknowledged and we thank Anita Starlight for typing the manuscript.

\section{References}

1 Creutzfeldt W, Arnold R. Somatostatin and the stomach: exocrine and endocrine aspects. Metabolism 1978; 27: suppl 1: 1309-15.

2 Ligumski M, Goto Y, Debas H, Yamada T. Prostaglandins mediate inhibition of gastric acid secretion by somatostatin in the rat. Science 1983; 219: 301-3.

3 Fordtran JS, Walsh JH. Gastric acid secretion rate and buffer content of the stomach after eating. J Clin Invest 1973; 52: 645-57.

4 Whittle BJR. Potential endogenous inhibitor of prostaglandin synthetase in plasma. Failure to inhibit cyclooxygenase in platelets and the gastric mucosa. $J$ Pharm Pharmacol 1978; 30: 467-8.
5 Bauminger S. Zor V, Lindner HR. Radioimmunological assay of prostaglandin synthetase activity. Prostaglandins 1973; 4: 313-24.

6 Bloom SR, Mortimer CH, Thormer MO et al. Inhibition of gastrin and gastric acid secretion by growthhormone release inhibiting hormone. Lancet 1974; 2: 1106-9.

7 Chew CS. Inhibitory action of somatostatin on isolated gastric glands and parietal cells. Am J Physiol 1983; 245: G221-9.

8 Gespach C, Bataille D, Dupont C, Rosselin G, Dutrilleau MC. The interaction of glucagon, GIP and somatostatin with cyclic AMP production system present in rat gastric glands. Biochim Biophys Acta 1982; 720: 7-16.

9 Soll AH. Specific inhibiton by prostaglandin $E_{2}$ and $I_{2}$ of histamine stimulated (14C) aminopyrine accumulation and cyclic adenosine monophosphate generation by isolated canine parietal cells. J Clin Invest 1980; 65: 1222-9.

10 Winship DH, Bernhard GC. Basal and histamine stimulated human gastric acid secretion: lack of effect of indomethacin in therapeutic doses. Gastroenterology 1970; 58: 762-5.

11 Levine Ra, Schwartzel EH. Effect of indomethacin on basal and histamine stimulated human gastric acid secretion. Gut 1984; 25: 718-22.

12 Coraggio $F$, Scarpato $\mathrm{P}$, Spiná $\mathrm{M}$, Lombardi $\mathrm{S}$. Somatostatin and ranitidin in the control of iatrogenic haemorrhage of the upper gastrointestinal tract. $\mathrm{Br}$ Med J 1984; 289: 224.

13 Lin TM, Evans DC, Schaan CJ, Root MA. Action of somatostatin on stomach, pancreas, gastric mucosal blood flow and hormones. Am J Physiol 1983; 244: G40-5.

14 Faivre J, Faivre $\mathrm{M}$, Lery $\mathrm{N}$ et al. Aspirin and gastrointestinal bleeding. Interest of plasma salicylate determination. Digestion 1979; 19: 218-20. 